\title{
Glossário da atividade extrativista no Estado do Acre: instrumentos de trabalho, alimentação, ervas e lendas
}

\section{Glossary of extractivist jargon in the State of Acre: tools, food, herbs, and legends}

\author{
Márcia Verônica Ramos de Macêdo* \\ Universidade Federal do Acre \\ Rio Branco, Acre, Brasil
Maria Cândida Trindade Costa Seabra**
Universidade Federal de Minas Gerais
Belo Horizonte, Minas Gerais, Brasil

\begin{abstract}
Resumo: Este estudo apresenta os resultados parciais do projeto de estágio pós-doutoral desenvolvido no Programa de Pós-Graduação em Estudos Linguísticos da Universidade Federal de Minas Gerais - UFMG, cujo objetivo é o de elaborar o Glossário da atividade extrativista com base na pesquisa efetuada no Centro de Estudos Dialetológicos do Acre, na Universidade Federal do Acre, nos idos de 1990. Tem como base teórica os pressupostos da Lexicologia, Lexicografia, Dialetologia e Sociolinguística. Utilizamos o método lexicográfico para a elaboração do glossário. A metodologia adotada foi a pesquisa de campo, com entrevistas dirigidas, através de um questionário semântico-lexical, sobre a atividade extrativista, que versavam desde o convívio em família até a atividade produtiva, modo de produzir a borracha até o processo de comercialização. Neste artigo descreveremos somente os campos lexicais dos instrumentos de trabalho, algumas ervas e lendas da floresta (MACÊDO, 2017). Após as entrevistas, foram feitas as transcrições grafemáticas e parte delas publicadas por Lessa (2002). O corpus compõe-se de 45 inquéritos organizados e publicados por Lessa (2002), coletados nas regiões dos Vales do Acre, Purus e Juruá e da Dissertação de Macêdo Sousa (2004), bem como de um corpus inédito de 10 horas de gravação da pesquisa realizada pela autora enquanto bolsista de Aperfeiçoamento Científico do CNPq. Toma como fundamentação teórica os estudos de Welker (2005), Biderman (1984), Isquerdo e Oliveira (2007) e Camacho (2008), sobre Lexicografia e Lexicologia; Pottier (1974), sobre os tipos de lexias; e Cardoso (2010) e Mota e Cardoso (2006), acerca da Dialetologia; além do modelo de verbete de Macêdo (2012) e Cunha (1982,) para a classificação etimológica. Utilizou-se da técnica do ARCGIS para a elaboração das cartas linguísticas. Os resultados são apresentados por meio de um glossário, tabelas, gráficos e cartas lexicais. As lexias sobre os instrumentos do seringueiro são classificadas em: 1. Simples: toco, cabilho, prancha, borracha, oito, tigela, vasilha, poronga, lamparina; 2. Compostas: pano virgem, pano vadiando, quebra jejum, perna direita, perna esquerda, margem direita, margem esquerda; 3. Complexas: lâmina de seringa, faca de seringa, cabo de arame, faca de seringa, lâmina de seringa, vasilha de colher, pé de bode, pé de burro, entre outras. São classificadas de acordo com suas origens (latim, espanhol, grego, italiano, francês ou desconhecida), além da dicionarização ou não das lexias e as dicionarizadas com outra acepção. Em relação às ervas foram selecionadas algumas, tais como: Chá de Alfavaca, Eucalipto, Casca da Copaíba, entre outras. No tocante às entidades da floresta foram encontradas: Caboclinho da mata, Mãe da seringueira, Mãe d'água, Caipora, Mapingari, Pai da Mata. Os resultados demonstram um total de, aproximadamente, 93 lexias, sendo: 29 relativas aos instrumentos de trabalho do seringueiro, 32 relativas à alimentação, 26 nomes de ervas utilizadas na cura da malária, febre, gripe, inflamações na garganta, entre outras, e, por fim, seis lendas específicas da região amazônica. São importantes o registro e o resgate do
\end{abstract}

*Professora do Mestrado Profissional em Letras - PROFLETRAS - Universidade Federal do Acre, Rio Branco, Acre, Brasil. E-mail: marciavestrela@gmail.com.

**Professora do Programa de Pós-Graduação em Estudos Linguísticos - POSLIN - Universidade Federal de Minas Gerais, Belo Horizonte, Minas Gerais, Brasil. E-mail: candidaseabra@gmail.com. 
vocabulário da atividade que colonizou o Estado do Acre, a fim de identificar a cultura regional e contribuir com o ensino de língua portuguesa e da dialetologia e lexicografia regional.

Palavras-chave: Dialetologia. Glossário. Extrativismo. Léxico.

\begin{abstract}
This paper presents the partial results of the postdoctoral training project developed in the Postgraduate Program in Linguistic Studies of the Federal University of Minas Gerais - UFMG, whose goal is to elaborate the Glossary of extractivist jargon, based on the research developed in the 90 s and carried out by the Center for Dialectological Studies of Acre at the Federal University of Acre. It uses as theoretical basis the contributions of Lexicology, Lexicography, Dialectology, and Sociolinguistics. The lexicographic method was used to create the glossary. The methodology adopted was the field research, with interviews conducted, through a lexical semantic questionnaire on the extractive activity that ranged from family life to productive activity, a way to produce rubber until the commercialization process. In this paper we will describe only the lexical fields of the working tools, some herbs and myths of the forest (MACEDO, 2017). After the interviews, the graphematic transcriptions were made and part of them published by Lessa (2002). The corpus is composed of 45 surveys organized and published by Lessa (2002) collected in the regions of the Valleys of Acre, Purus and Juruá and the Dissertation of Macêdo Sousa (2004), as well as 10 hours of unpublished recordings obtained during a research carried out by the author as a member of CNPq (The Brazilian National Council for Scientific and Technological Development) Scientific Improvement Scholar. It is based on the theoretical basis of Welker (2005), Biderman (1984), Isquerdo and Oliveira (2007), and Camacho (2008), on Lexicography and Lexicology; Pottier (1974), on lexias ; and Cardoso (2010) and Mota e Cardoso (2006), on Dialectology; in addition to the model of entry of Macêdo (2012) and Cunha (1982), for the etymological classification. The ARCGIS technique was used for the preparation of the linguistic charts. The results are presented through a glossary, tables, graphs and lexical charts. The lexias on the instruments of the seringueiro are classified in: 1. Simple: toco, cabilho, prancha, borracha, oito, tigela, vasilha, poronga, lamparina; 2. Compound: pano virgem, pano vadiando, quebra jejum, perna direita, perna esquerda, margem direita, margem esquerda 3. Complex: lâmina de seringa, faca de seringa, cabo de arame, faca de seringa, lâmina de seringa, vasilha de colber, pé de bode, pé de burro, among others. They are classified according to their origins (Latin, Spanish, Greek, Italian, French or unknown), in addition to the lexis and dicarization of dictionaries and dictionaries with a different meaning. Regarding the herbs, some were selected, such as: Chá de Alfavaca, Eucalipto, Casca da Copaíba, among others. Regarding the entities of the forest were found: Caboclinho da mata, Mãe da seringueira, Mãe d'água, Caipora, Mapingari, Pai da Mata. The results show a total of approximately 138 lexias, being: 29 related to the working tools of the rubber tappers, 33 related to food, 26 names of herbs used to cure malaria, fever, flu, throat inflammation, among others, and finally, six specific legends of the Amazon region. It is important to register and rescue the vocabulary of the activity that colonized the State of Acre in order to identify the regional culture and contribute to the teaching of Portuguese language and regional dialectology and lexicography.
\end{abstract}

Keywords: Dialecology; Glossary; Extractivism. Lexicon.

\title{
1 INTRODUÇÃO
}

Este artigo visa apresentar os resultados parciais do Glossário da atividade extrativista: instrumentos de trabalho, alimentação, ervas e entidades da floresta, como fruto do estágio pós-doutoral na Universidade Federal de Minas Gerais. O estudo baseia-se nos pressupostos da Lexicologia, Lexicografia, Dialetologia e Sociolinguística. Utiliza o método lexicográfico para a elaboração do glossário e o da geografia linguística para a elaboração das cartas léxicas. $\mathrm{O}$ corpus constitui-se da transcrição de 10 inquéritos inéditos somados às 45 entrevistas com seringueiros e seringueiras acreanos, analfabetos, nas faixas etárias: A - de 15 a 25 anos, B - de 26 a 36 anos e C - de 37 anos em diante, das quais 
resultaram os livros: A linguagem falada no Vale do Acre, A linguagem falada no $V$ ale do Purus e A linguagem falada no V ale do Juruá (LESSA, 2002) e As lendas da floresta contadas por seringueiros acreanos (MACÊDO; MACÊED SOUSA, 2007). Tem por finalidade resgatar a linguagem dessa atividade econômica da região e dos que atuam na mesma, visto que, atualmente, os seringueiros utilizam outras ferramentas, antes a poronga (substituída pela lanterna) e o mutá (substituído pela escada) para o exercício do fazer diário.

Nesse sentido, busca-se registrar essas lexias coletadas na época da pesquisa (década de 1990) com o intuito de contribuir com um resgaste linguístico e cultural dessa atividade bastante produtiva no estado do Acre.

O interesse em estudar a variante brasileira da língua portuguesa, sobretudo em sua modalidade falada, é uma preocupação antiga dos dialetólogos, entre os quais se destacam Amadeu Amaral, com o Dialeto caipira, publicado em 1920, o qual fez a primeira tentativa de descrever um falar regional.

\section{POR QUE RESGATAR ESTE LÉXICO?}

Podemos mencionar que o estudo do léxico extrativista - uma atividade tradicional muito antiga e muito importante no Estado do Acre - justifica-se, sobretudo, por ser essa atividade um meio de sobrevivência para a população da floresta, é uma das suas principais fontes de renda e de sustento. É, ainda, um resgate cultural por ser uma fonte rica de saberes populares, seja pelos instrumentos de trabalho do seringueiro, o modo de produção do látex, ou pelas ervas medicinais utilizadas nas curas das doenças, da alimentação e das entidades da floresta, como Mapinguari, Mãe da Mata e Caipora. Baseada nos conhecimentos empíricos e passados de geração a geração, essa atividade mantém características específicas no processo produtivo com o látex, com marcas culturais relevantes, mas que precisam ser descritas e registradas em verbetes, uma vez que se observa uma alteração no modo de executá-la como a atual forma de manejo da seringueira que produzem a borracha em forma de folha defumada, mais conhecida como FDL (folha de defumação líquida) e FSA (folha semi-artefato), e seu léxico, no nosso entender, precisa ser preservado para conhecimentos das futuras gerações e da história desse povo.

Do ponto de vista histórico, a economia acreana baseou-se no extrativismo que foi o grande responsável pelo povoamento da região quando da leva de cearenses em busca do "ouro preto" no Estado do Acre. Até 1903, essa região foi disputada pelo Brasil, Bolívia e Peru, quando então o Brasil comprou-a dos bolivianos por dois milhões de libras esterlinas. Daí o Estado passou a ser território brasileiro, mas só foi elevado à categoria de um estado em 1962. Além disso, parte dele é formada por mata intocável, protegida principalmente pelo estabelecimento de florestas de proteção integral, reservas indígenas e reservas extrativistas. Atualmente, a madeira é o principal produto de exportação do Estado, mas sua economia, ainda, é baseada no extrativismo, sendo o maior produtor brasileiro de borracha.

Assim, propomos este estudo lexical, lexicográfico e dialetal sobre a linguagem dos seringueiros de comunidades acreanas em três regiões do Estado, Vales do Acre, Purus e 
Juruá, a fim de identificar as possíveis variações e as principais características relacionadas à atividade desenvolvida - o extrativismo - a partir de enfoques lexicográficos e pluridimensional, uma vez que enfocará três variáveis: a diatópica, a diagenérica e a diageracional com a finalidade da feitura do glossário do extrativismo e de elaborar algumas cartas linguísticas.

Tão importante quanto a coleta dos dados para a análise e posterior fixação das características de um falar, em via de extinção, é a consciência de que só o surgimento dos resultados de outras pesquisas, sérias e imparciais, possibilita a comparação entre as variantes regionais, para a definição de um dialeto brasileiro.

Desse modo, compreende-se que é por meio da língua que o ser humano expressa suas ideias, as ideias de sua geração, da comunidade a que pertence, as ideias de seu tempo. A todo instante ele utiliza a língua, de acordo com a tradição que lhe foi transmitida e, desse modo, contribui para a inovação e/ou a conservação da linguagem. Na verdade, cada falante é, a um só tempo, usuário e agente modificador de sua língua, nela imprimindo marcas geradas pelas novas situações com que se depara. E, nessa perspectiva, salienta Câmara Jr. (1975): “a língua é uma parte da cultura, mas uma parte que se destaca do todo e com ele se conjuga dicotomicamente [...], é o resultado dessa cultura, ou, em súmula, é o meio para ela operar, é a condição para ela subsistir" (CÂMARA JR., 1975, p. 268-269).

Depreende-se, assim, que a língua engloba a cultura, comunica-a e transmite-a. Daí se infere que, para o real conhecimento de um grupo humano, não basta pesquisar a sua história, seus costumes ou o ambiente no qual vive determinada comunidade. É necessário observar a forma particular de o grupo manifestar a sua linguagem e, assim, representar, por meio dela, a realidade que o circunda.

A presente pesquisa toma como premissa a afirmação de Alvar (1961) de que "o estudo de uma língua não se esgota na investigação de seus aspectos estruturais, transcendendo o plano da frase e atingindo o universo da língua como instrumento de comunicação que se consubstancia no discurso" (ALVAR, 1961, p. 31).

Assim, o indivíduo, ao falar, transmite a mensagem contida em seu discurso, bem como uma série de dados que permite a um interlocutor atento não só depreender seu estilo pessoal - seu idioleto - mas também filiá-lo a um determinado grupo social.

Alvar (1961, p. 53) estabelece distinção entre o falar regional e o falar local. O primeiro caracteriza-se por ser a peculiaridade expressiva própria de uma região determinada, com traços de coerência própria de um dialeto. São, portanto, peculiaridades regionais da língua comum. O segundo possui estruturas linguísticas de traços pouco diferenciados, com matizes peculiares da estrutura regional, cujo uso está limitado a pequenas circunscrições geográficas, normalmente de caráter administrativo.

Disso, valemo-nos dos estudos dialetais. Como afirma Cardoso, “a Dialetologia é um ramo dos estudos linguísticos que tem por tarefa identificar, descrever e situar os diferentes usos em que uma língua se diversifica, conforme a sua distribuição espacial, sociocultural e cronológica" (CARDOSO, 2010, p. 15).

Ainda segundo a autora, 
O espaço geográfico evidencia a particularidade de cada terra, exibindo a variedade que a língua assume de uma região para outra, como forma de responder à diversidade cultural, à natureza da formação demográfica da área, à própria base linguística preexistente e à interferência de outras línguas que se tenham feito presentes naquele espaço no curso de sua história. (CARDOSO, 2010, p. 15)

Nesta pesquisa, serviram de índices identificadores da linguagem do seringueiro acreano os seguintes aspectos: a) a região da qual se origina; b) o grupo social do qual faz parte (seu grau de instrução, faixa etária, gênero, nível socioeconômico, atividade profissional); c) a situação (formal ou informal) em que se encontra. Abordamos, desse modo, fatores linguísticos, como unidade, diversidade, inovação, conservação, tipos de lexias e a etimologia; e extralinguísticos, como variações diatópicas, diagenéricas e diageracionais.

De acordo com Cardoso (2010, p. 19), "idade, gênero, grau de escolaridade, profissão, inserção social constituem-se em variáveis que, na perseguição de aspectos socioculturais, a dialetologia busca controlar e identificar". Além disso, "a apresentação cartográfica de tais dados põe lado a lado a informação diatópica e a informação sociolinguística”.

Desse modo, é possível afirmar que a Dialetologia e a Sociolinguística reconheceram, desde o início, a heterogeneidade linguística. Ambas buscam retratar a realidade linguística de um dado momento da história da língua e têm caminhado lado a lado, pois o que importa é descrever a língua e resgatar o fato linguístico do ponto de vista histórico-social.

Por outro lado, sabe-se que "toda língua histórica apresenta uma estrutura fônica, gramatical e léxica definida e distinta das demais. Nesse sentido, geralmente, em uma língua histórica, como a portuguesa, existem tipos fundamentais de diferenças internas a serem diferenciadas" (MACÊDO, 2012, p. 83-84). Citam-se as variações utilizadas neste artigo com base na autora citada:

1. Diferenças diatópicas, relacionadas às diferenças de espaço geográfico, como nos exemplos de Ferreira e Cardoso (1994, p. 12-13): bergamota, mexerica, tangerina para designar certa fruta cítrica, respectivamente no Rio Grande do Sul, Nordeste em geral, Rio de Janeiro;

2. Diferenças diastráticas, relativas às diferenças entre os distintos estratos socioculturais da mesma comunidade idiomática. Exemplos: pobrema por problema, poliça por policia, seje por seja, esteje por esteja, de uso frequente em grupos de baixa escolaridade (SILVA, 2003);

3. Diferenças diageracionais, relativas às diferenças de faixas etárias: anta (significando esperto, para uma geração de faixa etária mais alta, no Rio Grande do Sul) e tolo (para os cariocas em geral); vigir por viger, o alface por a alface, pespectiva por perspectiva, beneficiência por beneficência, com emprego disseminado por grupos escolarizados, de diferentes níveis e faixas etárias; fateco, casquinha, côdea, para designar a camada externa do pão, segundo se colheu no discurso informal 
de paraenses, cariocas, sendo côdea restrito a faixa etária mais elevada (SILVA, 2003);

4. Diferenças diagenéricas, relativas às diferenças de sexo (masculino ou feminino), como, por exemplo, no vocabulário do seringueiro acreano, no qual há uma tendência dos informantes do sexo feminino a fazerem uso do diminutivo para os instrumentos de trabalho do mesmo: facazinha ao invés de faca, laminazinha ao invés de lâmina, poronguinha no lugar de poronga, caxazinha ao invés de caixa, lamparinazinha ao invés de lamparina e assim sucessivamente, de acordo com Macêdo (2005, p. 157).

Além desses conceitos, utilizaram-se, ainda, os referenciais da Lexicologia e da Lexicografia, definidas a seguir.

A Lexicologia é definida como

o estudo científico do léxico, isto é, propõe-se a estudar o universo de todas as palavras de uma língua, vistas em sua estruturação, funcionamento e mudança, cabendo-lhe, entre outras tarefas: definir conjuntos e subconjuntos lexicais; examinar as relações do léxico de uma língua como universo natural, social e cultural; conceituar e delimitar a unidade lexical de base - a lexia - bem como elaborar os modelos teóricos subjacentes às suas diferentes denominações; abordar a palavra como um instrumento de construção e detecção de uma "visão de mundo", de uma ideologia, de um sistema de valores, como geradora e reflexo de sistemas culturais; analisar e descrever as relações entre a expressão e o conteúdo das palavras e os fenômenos daí decorrentes. (BARBOSA, 1991 apud ANDRADE, 2001, p. 191)

Câmara Jr. (1986, p. 158) afirma que Lexicologia é “o termo usado por alguns gramáticos para designar o estudo dos vocábulos, tanto em sua flexão, quanto nos processos para sua derivação e composição".

A Lexicologia tem como objetos básicos de estudo e análise a palavra, a categorização gramatical e a estruturação do léxico. Além disso, mantém uma estreita relação com a Semântica, pois se ocupa do léxico e da palavra, considerando a sua dimensão significativa. Faz também fronteira com a Morfologia, por se ocupar da problemática da formação das palavras; e com a Dialetologia e a Etnolinguística, ao passo que se debruça sobre o estudo da relação entre língua e cultura (BIDERMAN, 2001).

Tradicionalmente, os estudiosos da Lexicologia se ocuparam mais da problemática da formação de palavras e do estudo da criação lexical, os neologismos. A partir da década de cinquenta, muitas pesquisas foram realizadas em Estatística Léxica visando obter resultados aplicáveis ao ensino-aprendizagem do vocabulário.

A Lexicologia é definida, ainda, como "uma disciplina teórica e científica do léxico que é o conjunto de palavras (unidades lexicais) de uma dada língua” (SILVA, 2009, p. 88-89).

Por outro lado, tem-se a Lexicografia, que, de acordo com Biderman (2001, p. 17), é "a ciência dos dicionários". É uma atividade antiga e tradicional. A Lexicografia ocidental iniciou nos princípios dos tempos modernos. Embora tivesse precursores nos glossários latinos medievais, essas obras não passaram de listas de palavras explicativas que auxiliavam o leitor de textos da antiguidade clássica e da Bíblia na sua interpretação. 
Desse modo, este estudo é importante, sobretudo, devido ao interesse da autora, desde o ano de 1991, pela investigação lexicográfica e dialetológica, quando atuou como bolsista de aperfeiçoamento científico do CEDAC/CNPq de 1991 a 1992, pela feitura de um glossário na sua dissertação de Mestrado (2005), e outro na Tese de doutorado (2012), bem como compreende a validade do trabalho lexicográfico como forma de resguardar formas linguísticas fadadas ao desaparecimento.

Citamos, a seguir, os objetivos do estudo.

\section{OBJETIVOS}

O objetivo geral da pesquisa é contribuir com os estudos lexicológicos e dialetais do Acre e do país, através da identificação do léxico da atividade extrativista a partir de uma abordagem lexicográfica, dialetológica e sociolinguística, considerando fatores linguísticos e extralinguísticos, bem como descrever a vida do seringueiro acreano no seu fazer diário.

Como objetivos específicos, citam-se: (i) produzir um glossário da atividade extrativista com base nas lexias levantadas no corpus do projeto CEDAC e de livros sobre a temática, revistas e jornais antigos até o ano 2001; (ii) elaborar cartas linguísticas do léxico do seringueiro das comunidades acreanas a fim de traçar linhas de isoglossas dos três Vales da pesquisa; (iii) identificar os fatores linguísticos (unidade, diversidade, inovação, conservação, tipos de lexias) e extralinguísticos (localidade, gênero, idade) na linguagem do seringueiro acreano; e (iv) analisar as lexias quanto ao registro/não registro nos dicionários, classificação morfológica, a etimologia e o campo semântico.

\section{PROBLEMAS}

Os problemas apresentados foram: (i) a delimitação de subáreas dialetais é uma possibilidade viável em função do modelo de questionário lexical que é abrangente para a elaboração de cartas que fomentem um esboço de atlas linguístico?; (ii) o léxico do seringueiro acreano está sendo "reformulado" em função dos objetos que estão em desuso e/ou devido ao aparecimento de novos objetos?; e (iii) o desuso de alguns objetos e da forma de produção do látex pode levar à perda de identidade da atividade extrativista original?

\section{METODOLOGIA}

Como instrumento metodológico para o presente estudo, fez-se a pesquisa bibliográfica a partir da leitura de textos específicos sobre o assunto, e tomando por base a pesquisa de campo efetuada pelo Centro de Estudos Dialetológicos do Acre, nos idos de 1992 a 2001, sobre a atividade extrativista, na qual temos um resgate de 100h de gravação, bem como na produção dessa coleta com os três livros: A linguagem falada nos $V$ ales do Acre, Purus e Juruá (LESSA, 2002) e o livro As lendas da floresta contadas por seringueiros acreanos (MACÊEO; MACÊED SOUSA, 2007). 
O questionário tomou como base o campo semântico 'Homem', enfocando três pontos essenciais: 1. o seringueiro e os utensílios de trabalho; 2. o seringueiro, a alimentação, as ervas medicinais, a saúde e as entidades da floresta; 3. o seringueiro e a produção e comercialização, sendo que este último campo semântico, ainda, está em construção.

Foram entrevistados 45 informantes nascidos nas respectivas regiões ou que nela viveram desde os cinco anos de idade e com pais acreanos. A seleção considerou a variável gênero (homem e mulher), que exerciam profissões ligadas à atividade extrativista, em três faixas-etárias: 15 - 25 anos, 26 - 35 anos e de 36 anos em diante. As transcrições das entrevistas seguiram as normas das transcrições grafemáticas do projeto CEDAC.

Para a fundamentação teórica foram utilizados os referenciais da Lexicografia, Lexicologia, Sociolinguística e Dialetologia. Para a conceituação das lexias, utilizamos os dicionários da língua portuguesa de Ferreira e Houaiss (versão eletrônica), dicionários etimológicos, em especial o de Nascentes (1966) e o de Cunha (1982). O modelo do verbete é de autoria de Macêdo (2012) e requer: uma palavra entrada (lema), classificação morfológica, conceito do termo (se está ou não dicionarizado e com qual acepção), contexto, ponto de inquérito, iniciais do informante e origem (ainda em elaboração). O método para a elaboração das cartas léxicas será o da Geografia Linguística com base no modelo do programa computacional ARCGIS.

Os resultados são apresentados em forma de glossário e, no futuro, de cartas léxicas com traçado de isoglossas a fim de verificar o que é comum e divergente entre as três áreas da pesquisa. Também serão elaborados gráficos e tabelas acerca dos fatores linguísticos.

\section{RESULTADOS PARCIAIS DO GLOSSÁRIO DO EXTRATIVISMO}

Os resultados parciais demonstram um total de, aproximadamente, 94 lexias, sendo: 29 relativas aos instrumentos de trabalho do seringueiro, 33 relativas à alimentação, 26 nomes de ervas utilizadas na cura da malária, febre, gripe, inflamações na garganta, entre outras, e, por fim, seis das lendas específicas da região amazônica.

A nosso ver são importantes o registro e o resgate do vocabulário da atividade que colonizou o Estado do Acre, a fim de identificar a cultura regional e contribuir com o ensino de língua portuguesa e da dialetologia e lexicografia regional.

O glossário foi subdividido em campos semânticos e o verbete seguiu o modelo de Macêdo (2012), conforme os itens: lema (palavra entrada - verbete) em maiúsculas, negrito e seguido de ponto; classificação morfológica em caixa baixa; conceito do Houaiss eletrônico (2018); variação linguística quando ocorrer, em itálico; contexto entre aspas; número do questionário entre parênteses; e a origem.

Todas as lexias seguiram a ordem alfabética, por campo semântico. Ainda acrescentamos a origem de cada item lexical. Decidimos colocar o lema com a ortografia dicionarizada e as variações fonéticas e ortográficas somente no contexto. Apresentamos, a seguir, os itens coletados (em forma de glossário) até o momento, pois várias horas de gravação estão em fase de transcrição. 


\section{GLOSSÁRIO}

\subsection{CAMPO SEMÂNTICO: INSTRUMENTOS DE TRABALHO}

Bacia. s.f. Recipiente portátil de formato circular, oval, fundo chato e bordas relativamente altas, feito de louça, metal ou plástico, para usos associados à água e outros líquidos. "\#L ele leva a bacia [...]" (RB016BF). De origem latina.

Balde. s.m. Instrumento utilizado para fazer a coleta do leite da seringa retirada das árvores. "... só o balde... o balde... o saco pá pô o leite né..." (XA013AM). De origem desconhecida.

Cabide. s.m. Objeto de madeira utilizado para pendurar os objetos do trabalho do seringueiro como as tigelas, por exemplo. Variações: Toco. Toquinho. Cabilho. “... dêxa lá no tocozim... o toco se chama cabilho..." (MU159AM).

Cabo de Arame. s.m. Parte ou extremidade por onde se prende, segura ou maneja algo, composto por uma liga de cobre e zinco, a que se podem acrescentar ainda outros metais. "\#L tem um saco né... cabo de arame [...]" (AB139BM). De origem latina.

Cabrita. s.f. DOA. “... o primêro que eu levo... pa cortá... pa tirá o leite é a faca... a cabrita...” (RB002AM). De origem latina.

Caixa. s.f. Instrumento de madeira utilizado para coalhar a borracha recolhida. Variação: Cáxa. "\#L quando a gente chega em casa bota pa qualha nuNa cáxa [...]" (MU162AF). De origem latina.

Cangalha. Armação feita de madeira utilizada em cima dos animais para fazer o transporte da seringa, tendo dois lados. Variação: Cangaia. "... uma cangaia de pau eles... coloca em cima dos burro..." (AB137CF).

Cavador. s.m. Objeto de madeira onde é jorrado o leite da seringa e aos poucos ia de defumando até formar a bola da seringa. Variação: Cavadô. Pau. “... como é o cavador? é um pau... aí... pra defumá... num sabe...” (AB137CF).

Capanga. s.f. Pequena bolsa usada nas mãos ou presa à cintura e destinada a carregar objetos menores. "\#L eu levarra faca a espingarda e a capanga de lado né... [...]" (MU153CM). De origem africana.

Escada. s.f. Série de degraus de materiais diversos, que conduz a lugares altos e baixos. "\#L quano ia ficando alto usava a escada [...]" (SM128BF). De origem latina.

Estopa. s.f. Objeto utilizado para carregar outros instrumentos do seringueiro, espécie de saco feito desse material. Saco de pano ou Saco de estopa. "\#L sai pa cortá levarra a estopa [...]" (MU163BM). De origem latina.

Esmeril. s.m. Pedra utilizada para amolar ou afiar lâminas. "\#L é terçado esmeril... lâmina de seringa que é pa corta...[...]” (AB145AM). De origem italiana.

Espingarda. s.f. Arma de fogo portátil, de cano comprido e com coronha própria para apoiar no ombro. "\#L tem a espingarda pra nós i com ela de lada também [...]' (RB017CM). De origem francesa.

Faca. s.f. Instrumento constituído por lâmina cortante presa a um cabo. "\#L nóis levarra faca... [...]" (AB137CF). De origem desconhecida. 
Fornalha. s.f. Objeto de barro utilizado para defumação. Variação: Fornaia de barro. “... fornaia de barro assim... um coisão assim dessa altura...” (AB137CF).

Lâmina de Seringa. s.f. Pedaço de metal ou de outra matéria dura, extremamente delgado e chato, destinado a fins e usos diversos. Variação: Faca de seringa. "\#L lâmina de seringa que é pa cortá... [...]" (AB145AM). De origem latina e grega (lâmina, do latim/seringa, do grego).

Poronga. s.f. Uma luminária, uma lamparina que os seringueiros usam na cabeça para percorrer as estradas da seringa na floresta amazônica. Variação: Lamparina. "\#L Com uma poronga na cabeça [...]" (AB135CM). De origem espanhola.

Panela. s.f. Recipiente quase sempre redondo, largo e de altura variável, dotado de alças ou cabo. "\#L ele leva a bacia... a panela [...]" (RB016BF). De origem latina.

Pé de Bode. s.m. Não dicionarizado. "\#L ah... ah pra colhê aí leva o pé de bode pra tirar tigela né... [...]” (RB017CM). De origem latina e desconhecida (pé, do latim/bode, origem desconhecida).

Saco. s.m. Receptáculo de pano, papel, couro, borracha ou material plástico, aberto apenas por cima. “\#L usava balde e o saco [...]” (PC006AF). De origem latina.

Terçado. s.m. Espada curta e larga, facão grande. Variação: Teçadim. "\#L um teçadim de baiNa... [...]" (RB005BM). Originada por um processo de derivação sufixal (terça + -ado). Tigela. s.f. Vaso côncavo de barro, metal, geralmente desprovido de asas. Variação: Vasilha de colhê. "\#L quais os objetos/ \#D sim \#L tigela [...]" (AB139BM). De origem latina.

Tocozim. s.m. No corte de qualquer planta, parte que permanece presa ao solo, pau curto, cacete. Variação: Cabilho. "\#L não deixa lá no tocozim... o toco se chama cabilho [...]" (MU159AM). De origem desconhecida.

Prancha. s.f. Instrumento de madeira utilizado para coalhar e fazer a borracha com auxílio de outro leite de outras árvores. Forma mais simples de fazer a seringa. Variação: Caixa. "... como faz a prancha? faiz a cáxa... tipo a cáxa pra botá qualqué côsa... aí tapa os buraco... aí roga o lête alí dentro...” (SM128BF).

Prensa. s.f. Ato de prensar a seringa já coalhada. Impresa. “... coalha e imprensa em dez minutos..." (XA013AM).

Saco. s.m. Instrumento utilizado para armazenar o leite da seringa. “... aí a gente vira a boca do saco... aí põe o leite dento..." (RB002AM).

Seringa. s.f. Madeira de onde se extrai o látex. Variação: Seringueira. “... A seringa... quando não é boa a gente tem que pegá lá em cima...” (XA013AM).

Tigela. s.f. Objeto colocado na árvore para escorrer a seringa para o saco. Variação: Torno. “... é... o leite caí na tigela... escorrê...” (XA013AM).

Torno. s.m. Objeto colocado na árvore para escorrer a seringa para o saco. Espécie de tigela. "... as tigela... se chama o torno..." (AB137CF).

\subsection{CAMPO SEMÂNTICO: ALIMENTAÇÃO}

Abobrinha. s.m. Comum às plantas do gên. Abóbora, da fam. das cucurbitáceas, que compreende uma espécie apenas, conhecida como abóbora-do-campo. "\#L ah a gente 
plantava a ceboliNa... o côve... sempre conseguia a semente do oface... a abobriNa... [...]" (AB142BF).

Açaí. s.m. Palmeira cespitosa de até $25 \mathrm{~m}$ (Euterpe oleracea), nativa da Venezuela, Colômbia, Equador, Guianas e Brasil de estipe anelado e frutos roxo-escuros de polpa comestível, assim como o palmito. \#L era... e fora os das ôtas irmã né que às veize tombém juntarra mar os das miNas irmã e nóis ia tirá açaí... patoá [...]” (AB137CF).

Anta. s.m. ND \#L matava caça... anta... era porco... veado... todo tipo de caça da mata $[\ldots] "$ (AB139BM).

Arroz. s.m. Erva ereta de até $1 \mathrm{~m}$ (Oryza sativa), da fam. das gramíneas, com flores em espiguetas e cariopsescoriáceas, provável origem asiática e cultivada há mais de 5.000 anos. "arroz também... arroz do mermo jeito do milho... arroz dá trabalho né [...]" (AB137CF).

Banana. s.m. Fruto da bananeira. "\#L plantarra roça... plantava primêramente o arroize... o milho... a roça... feijão... banana... [...]" (AB136CF).

Banha de porco. s.m. Gordura animal do porco. Variação: BaNia de porco. \#L: baNia de porco... mamãe engordava... nóis prantarra aí colhia o milho e a mamãe engordarra o porco" (AB137CF).

Cana. s.f. Colmo de várias plantas da família das gramíneas, como o da cana-de-açúcar e o dos bambus e também de algumas plantas de outras fam., como o ratã. \#L plantava mandioca... roça né e milho pa dá pás galiNa e a cana às veiz nóis plantava... era assim [...]" (MU159AM).

Carne de caça seca conservada no sal. s.m. Charque feito com bastante sal e ressecado ger. em estufa. "\#L é terçado esmeril... lâmina de seringa que é pa corta...[...]" (AB145AM). De origem italiana.

Cará. s.m. Comum a diversos peixes teleósteos perciformes da fam. dos ciclídeos, encontrados em rios e lagos, sendo ger. ornamentais; cará. "\#L era... nóis pegarra assim piaba ...nóis pegarra cará... assim mandim... esses pêxim assim [...]” (AB137CF).

Farinha seca. s.m. DOA. "\#L era... a bóia que levava pra estrada era fariNa seca... fariNa com açúca... era assim... [...]” (MU152CM).

Feijão. s.m. Fruto do feijoeiro; vagem, fava, legume. “\#L: prantavo roça... milho... fejão... arroiz [...]" (SM128BF).

Gado. s.m. Conjunto de quadrúpedes domesticados (carneiros, cavalos, bois, cabritos etc.) que se têm como propriedade ou que se criam para uso; rebanho. "\#L criavo porco... gado... nóis criava lá [...]" (MU163BM).

Galinha. s.f. Fêmea do galo. Variação: GaliNa. "nóis criava... nossa criação lá só era galiNa... porco... era só assim [...]” (MU159AM).

Gramichó. s.m. ND. "\#L sim tipo o açúca... com aquelas pedriNa... a gente chama gramichó e a rapadura é na forma [...]” (MU152CM).

Jabuti. s.m. Grande quelônio florestal encontrado na Amazônia e no leste do Brasil, com carapaça marrom, de até $82 \mathrm{~cm}$ de comprimento e centro dos escudos e escamas dos membros anteriores amarelos ou alaranjados. Geralmente serve de alimento ao seringueiro e família. Variação: cágado, carumbé, jabuti-carumbé. “\#L nóis caçarra só jabuti e paca que nóis não sabia atirá né [...]" (AB137CF). 
Mandim. s.m. DOA. "\#L era... nóis pegarra assim piaba ...nóis pegarra cará... assim mandim... esses pêxim assim [...]" (AB137CF).

Mandioca. s.f. Arbusto (Manihotesculenta) da fam. das euforbiáceas, nativo da América do Sul, de folhas membranáceas, inflorescências ramificadas e frutos capsulares, cultivado pelas raízes tuberosas, muito semelhantes às do aipim e tb. ricas em amido e de largo emprego na alimentação, embora sejam geralmente mais venenosas e frequentemente usadas apenas para a produção de farinha de mandioca, farinha-d'água e ração animal. Variação: GaliNa. "\#L plantava mandioca... roça né e milho pa dá pás galiNa e a cana às veiz nóis plantava... era assim [...]” (MU159AM).

Macaxeira. s.m. Arbusto da família das euforbiáceas, nativo da América do Sul, de folhas membranáceas, inflorescências ramificadas e frutos capsulares, cultivado pelas raízes tuberosas, muito semelhantes às do aipim e tb. ricas em amido e de largo emprego na alimentação. "\#L: a pessoa pega... arranca a macaxera... descasca e cerva no moto e torra [...]” (MU162AF).

Mel. s.m. Fluido açucarado, viscoso, de cor marrom-amarelada, produzido por várias espécies de abelha a partir do néctar das flores, e que é us. como alimento. "\#L fazia no seringal... mel... rapadura... dependia da engioca [...]" (MU152CM).

Milho. s.m. Erva anual de até $3 \mathrm{~m}$, da família das gramíneas, com folhas lanceoladas, gerando espigas com grãos brancos, amarelos, avermelhados ou azulados. "\#L planta o arroizim... o milho né... mais sempre o méis da planta é o méis de otubro [...]” (AB142BF). Nambu. s.m. DOA. \#L veado que a gente matava... agora no verão assim era embiara que às veiz fica difício é a nambu... mutum [...]" (MU163BM).

Paca. s.f. Grande roedor noturno encontrado na região do Vale do Purus, próximo a rios, com cerca de $70 \mathrm{~cm}$ de comprimento e até $13 \mathrm{~kg}$, cauda pequena e não visível e pelagem pardo-amarronzada, com três a quatro listras longitudinais formadas por grandes manchas brancas. \#L nóis caçarra só jabuti e paca que nóis não sabia atirá né [...]” (AB137CF).

Patoá. s.m. DOA. “\#L era... e fora os das ôtas irmã né que às veize tombém juntarra mar os das miNas irmã e nóis ia tirá açaí... patoá [...]” (AB137CF).

Peixe. s.m. Comum aos animais vertebrados, aquáticos, que possuem os membros transformados em nadadeiras sustentadas por raios ósseos, esqueleto ósseo ou cartilaginoso, coração dividido em duas cavidades e respiração branquial. Variação: Pexe. "\#L negóço de pêxe... que é o que é mais comum assim que a rente pega mais é pêxe [...]" (SM128BF).

Pé-de-moleque. s.m. Doce consistente feito de açúcar ou rapadura com amendoim torrado. \#L aí a gente coloca as mandioca de molho aí lavava aquela massa aí fazia pé de moleque pa quebrá o jejum de manhã com ovo... [...]" (MU156BF).

Pepino. s.m. Fruto do pepineiro \#L a gente plantava roça... plantava milho... arroiz... mamão e às veiz pepino [...]" (AB139BM).

Pirão. s.m. Papa de farinha de mandioca feita ger. com caldo temperado provindo de uma cocção de legumes e/ou carnes (peixe, ave ou animais de carne vermelha). "\#L bóia de seringuêro é um pirão assim bem cedo né... aí ele sai com aquele pirão quando chega no fecho da estrada come Oto... [...]” (MU159AM). 
Porco-do-mato. s.m. Mamífero artiodátilo (Tayassu pecari) da fam. dos taiaçuídeos, diurno e terrestre, encontrado desde o sul do México até o nordeste da Argentina; com cerca de $1 \mathrm{~m}$ de comprimento e pelagem negra com o queixo branco. Variação: Porquim. “\#L: sempe a rente vai esperá assim de noite nas comida... aí mata caça... veado... porquim $[\ldots] ”(\mathrm{AB} 137 \mathrm{CF})$.

Rapadura. s.m. Açúcar mascavo solidificado em forma de um pequeno tijolo. "\#L já teNo cento e poças cova de cana plantada... porque aqui a gente... eu faço rapadura... faço mel... faço gramichó... tudo eu faço né... [...]" (MU152CM).

Surubim. s.m. Comum a alguns bagres da fam. dos pimelodídeos dos gên. Pseudoplatystoma e Sorubim, que possuem a cabeça muito grande e achatada e corpo formado por placas ósseas. "\#L rapaiz... surubim a gente pegava esses pêxim pequeno mermo [...]" (MU159AM).

Tapioca. s.m. Fécula comestível, extraída das raízes da mandioca ou do aipim, com que se preparam pratos doces e salgados. "\#L aí a gente faiz a tapioca... aí assim pra... pa fazê coisa assim pra quebrá jejum que a gente num pode mermo comprá né [...]” (MU156BF). Do tupi tïpi'og no sentido de 'sedimento, coágulo da mandioca crua coalhada'.

Veado. s.m. Comum a diversos mamíferos ruminantes da fam. do cervídeos, de coloração geralmente amarronzada, cornos ramificados ou simples, presentes apenas nos machos, pata com quatro dedos, pernas longas e cauda curta. “\#L: sempe a rente vai esperá assim de noite nas comida ... aí mata caça ... veado ... porquim ... [...]” (AB137CF).

\subsection{CAMPO SEMÂNTICO: ERVAS}

Cachaça com Jucá. s.m. Jucá é m. q. pau-ferro. “\#L é... cachaça com jucá... chuá e cabaciNa é um remede... num sinto nem dô no corpo... [...]” (MU152CM). Do tupi yu'ka no sentido de 'matar'.

Carrapicho Águia. s.m. Plantas da família das compostas, gramíneas, malvácease tiliáceas, todas com frutos capsulares articulados, com pequenos espinhos ou pelos, que aderem às roupas e aos pelos dos animais. "\#L: pa malária era só o chá daquele... carrapicho águia [...]" (AB136CF).

Casca da Copaíba. s.m. Infusão preparada com outros tipos de ervas \#L nas mata... o Chá da: da... a Casca da Copaíba... do Cumaru de Chêro tamém serve [...]" (SM128BF).

Chá de Alfavaca. s.m. Infusão preparada com outros tipos de ervas. Variação: Chá de afavaca. "\#L: negóço de Chá de Afavaca... chá de qualqué côsa do mato que sirva [...]" (SM128BF).

Chá de Boldo. s.m. Infusão preparada com a árvore (Peumus boldus) da família das monimiáceas, nativa do Chile, de folhas lanceoladas e frutos doces, especialmente cultivada pelos ramos e folhas, de que se faz chá, muito us. contra os males digestivos. Variação: Boldo-do-chile, folha-de-boldo. \#L às veiz usa aquele remedizin... aquele Chá de Boldo né... diz que resolve um pôco pa inflamação... figo... [...]” (AB139BM).

Chá da Folha da Laranja. s.m. Infusão preparada com folha da laranjeira. "\#L: a folha da laranja serve de calmante... calma tamém a febre [...]" (MU159AM). 
Chá de folha de limão. s.m. "\#L servia... pro... pra negóço de gripe... uma febre a... um Chá da Folha do Limão [...]" (SM128BF).

Chá de folha de mamão. ND. Infusão preparada com folha do mamão. "\#L quano tem febre forte pa... pó Chá da Foia do Mamão [...]” (MU156BF).

Chazinho do mato. s.m. Infusão preparada com outros tipos de ervas. Variação: Chą̧im do mato. \#L assim c'um Chazim do Mato ... só o Chazim do Mato [...]” (AB137CF).

Chá da Mata. s.m. Infusão preparada com vários tipos de ervas. "\#L pra malária se usavo píula tamém e chá... Chá da Mata [...]” (SM128BF).

Chá da Raiz do Açaí. s.m. ND. “\#L nóis usava é raiz de açaí... fazia o chá da raiz do açaí [...]" (AB136CF).

Chá de Carmelitano. s.m. DOA. \#L: pa febre... dô de cabeça... é Chá de Carmelitano... $[\ldots .$. " (AB136CF).

Chichuá. s.m. ND. “\#L coNeço... coNeço quina-quina... chichuá... pois é tudo é reméde. $[\ldots .$.$] (MU152CM).$

Cibalena. s.m. ND. “\#L: às veiz uma planta que a gente chama até Cibalena uma foiNia assim... tipo assim um malvarisco [...]" (AB145AM).

Cumaru Cheiro. s.m. Infusão preparada com outros tipos de ervas. \#L: nas mata... o Chá da: da... a Casca da Copaíba... do Cumaru de Chêro tamém serve [...]" (SM128BF).

Dipirona. s.m. DOA. "\#L essa que chama dipirona que às veiz tá queimano de febre faiz aquele chá e já soa né... tem o hortelã... tem esse picão... tem vários tipo de reméde... [...]" (AB142BF).

Espera Aí. s.m. DOA. \#L é um... um mato que tem com o nome de Espera Aí... e esse... pa febre... pa pessoa Pará de provocá... tudo serve" (MU162AF).

Eucalipto. s.m. De madeira amarela a vermelha, folhas coriáceas, geralmente lanceoladas e com glândulas oleíferas, flores freq. em umbelas e frutos capsulares. Variação: Acalipe. “\#L serve pa tanta coisa... serve pa a gente quano tá com gripe diz o pessoal que serve $[\ldots] ”$ (MU159AM).

Jenipapo. s.m. Fruto do jenipapeiro, uma baga subglobosa, geralmente amarelopardacenta, com polpa aromática, comestível. "\#L: ah... mais a gente tiNa que usá aquele rapa de jenipapo... [...]" (AB142BF).

Pau Milagroso. s.m. ND. \#L um Pau Milagroso é uma... um pé de pranta que.... que a rente arruma... aí pranta... aí do quando a gente tá c'um febre a rente rola um pedacin dele e bate e bota no fogo pa fazê chá pa bebê [...]" (MU162AF).

Picão. s.m. Erva da família das compostas, nativa do Brasil (MG, GO), de folhas serreadas e flores amareladas, em corimbos paniculados; amor-de-negro. "\#L: é sezão... é isso mermo... aí curava com aquilo e chá da mata... tal de picão... [...]” (AB142BF).

Quinaquina. s.m. Árvore (Ladenbergia undata) da família das rubiáceas, nativa da Venezuela, com casca us. como sucedânea da quina, folhas ovadas ou elípticas, coriáceas, e flores brancas, em panículas corimbosas. "\#L coNeço... coNeço quina-quina... chichuá... pois é tudo é reméde.. [...]” (MU152CM). De orig. controversa. Para Nasc., de quích. kinakina no sentido de 'casca'.

Quipi. s.m. ND. "\#L tem aquela catinguiNa ativa... aquilo acaba constipação... dô de cabeça... bom pra dô de dente... pra tudo [...]” (SM117CM). 
Remédio Caseiro. s.m. Substância ou recurso utilizado para combater uma dor, uma doença “\#L: ensina a fazer: casêro... remédio casêro [...]” (SM128BF).

Sabugueiro. s.m. Arbusto melífero com propriedades purgativas, drásticas e eméticas, folhas compostas e flores aromáticas, alvas. Variação: Sabuguêra. "\#L: às veiz a gente faiz o chá assim de uma... de uma planta que chamo Sabuguêra assim pa febre... pa dô de cabeça é bom [...]" (AB145AM).

Sumo do Mastruz. s.m. m.q. Mastruço. Erva de até $50 \mathrm{~cm}$ (Coronopus didymus), da fam. das crucíferas, vilosa e fétida, com folhas penatipartidas, flores freq. assépalas e síliquas bilobadas, nativa das Américas e cultivada por propriedades excitantes, peitorais, vermicidas e antiescorbúticas. Variação: Mastruço-do-brasil, mastruそ, masturço, mentrasto, mentruz: \#L fazia o sumo do mastruiz e dava [...]" (SM128BF). Do lat. vulgar *masturtiu.

\subsection{CAMPO SEMÂNTICO: ENTIDADES DA FLORESTA}

Caboclinho da mata. s.m. ND. Variação: Caboquim. “\#L eu já sim seNora que ele... que ele anda mar as caça... anda no mei das caça... [...] o dia da semana santa que dizem que ele num gosta que mate as caça... [...]" (AB137CF).

Caipora. s.f. Entidade fantástica da mitologia tupi, muito difundida na crença popular, talvez derivada da crença no curupira, do qual seria uma variante, e que é associada às matas e florestas e aos animais de caça, dele se dizendo que aterroriza as pessoas e é capaz de trazer má sorte e mesmo causar a morte. Variação: Caapora. “\#L coNeço... coNeço quina-quina... chichuá... pois é tudo é reméde.. [...]” (MU152CM). Do tupi kaa'pora no sentido de 'habitante do mato'.

Mãe d'água. s.f. ND. \#L: dize que ela é uma velha bem alviNa [...]” (AB137CF).

Mãe da Seringueira. s.f. ND. \#L diziam que diz que ela... ela... quano a pessoa cortarra demais néra ambicioso pra fazê aquelas munta borracha diz que ela apresentarra aquelas pessoa né... maise eles lá apresentarra mais quem cortarra pôco num... [...]” (AB137CF).

Mapinguari. s.m. Gigante lendário de formas semelhantes às do homem, o qual persegue para devorar especialmente a cabeça, e contra o qual o protegem seus grandes pelos espalhados por todo o corpo como um escudo impenetrável. “\#L: não... Mapinguari eu já ôvi falá mais num é pra cá... Mapinguari é só pro Mato Grosso pra essas mata que é de... que num tem cipó... [...]” (MU152CM).

Pai da Caça. s.m. ND. \#L eu já ouvi falá no Pai da Caça... Mãe da Madêra... [...]" (MU162AF).

De acordo com as lexias coletadas até aqui, temos: 29 referentes aos instrumentos de trabalho, 32 referentes à alimentação, 26 no tocante às ervas e 6 (seis) referentes às entidades da floresta (lendas), sendo os itens de alimentação os de maior frequência.

\section{CONSIDERAÇÕES FINAIS}

O estudo do léxico extrativista aborda uma atividade tradicional muito antiga e muito importante para o Estado do Acre, sobretudo como meio de sobrevivência para a 
população da floresta, que é uma das suas principais fontes de renda e de sustento de pessoas da região. É, ainda, uma fonte rica de saberes populares, seja pelos instrumentos de trabalho do seringueiro, pelo modo de produção do látex, ou pelas ervas medicinais utilizadas nas curas das doenças, da alimentação e das entidades da floresta, como Mapinguari, Mãe da Mata e Caipora, entre outras. Baseada nos conhecimentos empíricos e passados de geração a geração, essa atividade mantém características específicas no processo produtivo com o látex, com marcas culturais relevantes, como as que foram descritas e registradas nos verbetes. Observa-se, no entanto, que algumas lexias estão em desuso, pois a forma também de se produzir o látex foi modificada da década de 1990 para cá. Houve uma alteração no modo de executar a atividade, pois atualmente é mais comum produzirem a borracha em forma de folha defumada, mais conhecida como FDL (folha de defumação líquida) e FSA (folha semi-artefato), e, consequentemente, seu léxico vem sendo modificado, pois os objetos não são os mesmos, substituíram o mutá pela escada, a poronga pela lanterna, entre outros, e percebemos a necessidade de o léxico ser registrado para conhecimentos das futuras gerações e da identidade histórica do seringueiro acreano.

Do ponto de vista histórico, sabemos que a economia acreana baseou-se no extrativismo, que foi o grande responsável pelo povoamento da região quando da leva de cearenses em busca do "ouro preto" no Estado do Acre. Até 1903, essa região foi disputada pelo Brasil, Bolívia e Peru, quando então o Brasil comprou-a dos bolivianos por dois milhões de libras esterlinas. Com este fato o território do Acre passou a ser território brasileiro, e foi elevado à categoria de Estado somente no ano de 1962. Além disso, parte dele é formada por mata intocável, protegida principalmente pelo estabelecimento de florestas de proteção integral, reservas indígenas e reservas extrativistas.

Atualmente, a madeira é o principal produto de exportação do Estado, mas sua economia ainda é baseada no extrativismo, sendo considerado o maior produtor brasileiro de borracha, e os seringueiros continuam sofrendo com as mazelas de doenças como a malária, febre amarela, hepatites, entre outras, e utilizam-se das ervas que a mata, por hora, conserva. Por fim, a pesquisa demonstra que o universo do léxico extrativista é rico e outras lexias serão acrescidas ao Glossário da atividade extrativista a que se propõe o estudo.

\section{REFERÊNCIAS}

ALVAR, Manuel. Hacia los conceptos de lengua, dialecto y hablas. Nueva Revista de Filologia Hispânica, México, D.F. \& Austin, Texas, v. 15, p. 51-60, jan./jun. 1961.

ANDRADE, Maria Margarida de. Lexicologia, terminologia: definições, finalidades, conceitos operacionais. In: OLIVEIRA, Ana Maria Pinto Pires de; INQUERDO, Aparecida Negri. (Orgs.). As ciências do léxico: lexicologia, lexicografia, terminologia. $2^{\mathrm{a}}$ ed. Campo Grande: Ed. UFMS, 2001, p. 191-200.

BARBOSA, Maria A. Lexicologia, lexicografia, terminologia, terminografia: identidade científica, objeto, métodos, campos de atuação. In: Simpósio Latino Americano de Terminologia - II e 
Encontro Brasileiro de Terminologia Técnica-Científica - I. Anais. Brasília: IBICT, 1990, p. 153.

BIDERMAN, M. T. C. As ciências do léxico. In: OLIVEIRA, Ana Maria Pinto Pires de; ISQUERDO, Aparecida Negri. (Orgs.). As ciências do léxico: lexicologia, lexicografia, terminologia. Campo Grande: Ed. UFMS, 2001, p. 13-22.

CÂMARA JR., J. Mattoso. Língua e cultura. In: CÂMARA JR., J. Mattoso. Dispersos. $2^{\mathrm{a}}$ ed. Rio de Janeiro: Fundação Getúlio Vargas, 1975.

CÂMARA JR., J. Mattoso. Dicionário de lingüística e gramática: referente à língua portuguesa. $13^{\text {a }}$ ed. Petrópolis: Vozes, 1986.

CARDOSO, Suzana Alice Marcelino. Geolinguística: tradição e modernidade. São Paulo: Parábola, 2010.

CUNHA, Antônio Geraldo da. Dicionário etimológico nova fronteira da língua portuguesa. Rio de Janeiro: Nova Fronteira, 1982.

HOUAISS, Antônio. Dicionário Honaiss da língua portuguesa. Rio de Janeiro: Objetiva LTDA, 2001.

HOUAISS, Antônio. Dicionário Honaiss da língua portuguesa. Rio de Janeiro: Objetiva LTDA, 2010. Disponível em: <http://houaiss.uol.com.br/busca.jhtm>. Acesso em: nov. 2018.

LESSA, L. G. (Org.). A linguagem da pesca no Vale do Juruá. Rio de Janeiro, 2002.

LESSA, L. G. (Org.). A linguagem da pesca no V ale do Purus. Rio de Janeiro, 2002.

LESSA, L. G. (Org.). A linguagem da pesca no Vale do Acre. Rio de Janeiro, 2002.

MACÊDO, Márcia Verônica Ramos de. Aspectos dialectológicos e lexicográficos do Atlas Etnolingüístico do Acre. 2005, 186 f. Dissertação (Mestrado em Linguística Aplicada). Campus de Guajará Mirim. Universidade Federal de Rondônia, Guajará-Mirim - RO.

MACÊDO, Márcia Verônica Ramos de. A constituição de subáreas dialetais no falar da Babia. 2012, 460 f. Tese (Doutorado em Letras e Linguística). Instituto de Letras Universidade Federal da Bahia, Salvador - BA.

NASCENTES, Antenor. Dicionário etimológico da língua portuguesa. Rio de Janeiro, 1966.

SILVA, Moisés Batista. Glossário dos termos de indústria do sal no Rio Grande do Norte. In: ARAGÃO, Maria do Socorro Silva (Org.). Estudos em lexicologia, lexicografia, terminologia e terminografia. Fortaleza: UFC/MÍDIA, 2009, p. 15-24.

SILVA, Regina Maria Furquim Freire da Silva. Terminologia e lexicalização: proporcionalidade e divergências. 2003. 160 f. Dissertação. (Mestrado em Lingüística). Universidade de Brasília, Brasília.

Recebido em: 28/02/2019

Aprovado em: 07/06/2019

Publicado em: 28/09/2019 